\title{
Kisspeptin/G protein-coupled receptor-54 system as an essential gatekeeper of pubertal development
}

\author{
Young-Jun Rhie, MD, PhD \\ Department of Pediatrics, \\ Korea University Ansan Hospital, \\ Korea University College of Medicine, \\ Ansan, Korea
}

\begin{abstract}
Puberty is the end-point of a complex series of developmental events, defined by the dynamic interaction between genetic factors and environmental cues, ultimately leading to the attainment of reproductive capacity. Kisspeptins, products of the KISSI gene, were originally identified as metastasis suppressor peptides with the ability to bind G protein-coupled receptors (GPR54). In 2003, loss-of-function mutations of the GPR54 gene were found in patients with hypogonadotropic hypogonadism. This finding triggered study of the role of the kisspeptin/GPR54 system as an essential gatekeeper of control of reproduction and pubertal development. Kisspeptins are very potent elicitors of gonadotropin secretion, primarily through stimulation of gonadotropin-releasing hormone release. KISS1 also functions as an essential integrator for peripheral inputs, including gonadal steroids and nutritional signals, and for controlling GnRH and gonadotropin secretion. Whether the kisspeptin/GPR54 system is the trigger for puberty onset and/or it operates as integrator and effector of up-stream regulatory factors warrants further investigation.
\end{abstract}

Keywords: Puberty, Gonadotropin-releasing hormone, Gonadotropins, Kisspeptin, G protein-coupled receptor-54, Leptin

\section{Introduction}

Puberty is a complex and coordinated biologic process of sexual development that lead to full activation of the gonadotropin-releasing hormone $(\mathrm{GnRH})$ pulse generator, enhanced gonadotropin secretion, complete gonadal maturation and function, and attainment of reproductive capacity ${ }^{1,2)}$. Multiple determinants of pubertal development have been identified, which include not only genetic factors but also endogenous signals (e.g., energy status) and environmental cues ${ }^{1,3)}$, whose dynamic interplay is responsible for the timing of puberty onset and its eventual deviations (precocious, delayed or absent puberty). The activation of pulsatile GnRH secretion from specialized hypothalamic neurons to stimulate hormonal cascades and gonadal activation is a key event in the onset of puberty ${ }^{4)}$. But, the ultimate mechanisms underlying the increase in pulsatile GnRH secretion at puberty are yet to be fully elucidated ${ }^{5)}$.

Besides central regulators, it is well known that activation of the reproductive axis at puberty is extremely sensitive to fat reserves and the metabolic status ${ }^{6,7)}$. This critical information is signaled to the brain mainly through peripheral hormones from the adipose, gastrointestinal tract and pancreas ${ }^{8)}$. A critical role of leptin has been substantiated in the last few years. Thus, leptin functions as an essential permissive factor for pubertal development ${ }^{6,9)}$. This action of leptin upon the gonadotropic axis is primarily conducted via the hypothalamic GnRH system. GnRH neurons themselves, however, do not express leptin receptors ${ }^{9}$, suggesting the involvement of intermediate circuits and signals, the identity of which has yet to be completely

Recently, kisspeptins, the peptide products of KISS1 gene, and their putative receptor, G Accordingly, the trigger of puberty remains to be identified. elucidated.
Address for correspondence:
Young-Jun Rhie, MD, PhD
Department of Pediatrics,
Korea University Ansan Hospital,
Korea University College of
Medicine, 123 Jeokgeum-ro,
Danwon-gu, Ansan 425-707, Korea
Tel: +82-31-412-4846
Fax: +82-31-405-8951
E-mail: human21@korea.ac.kr
Received: 10 June, 2013

Accepted: 13 June, 2013

This is an Open Access article distributed under the terms of the Creative Commons Attribution Non-Commercial License (http://
creativecommons.org/licenses/by-nc/3.0) which permits unrestricted non-commercial use, distribution, and reproduction in any medium, provided the original work is properly cited.
ISSN: 2287-1012(Print) ISSN: 2287-1292(Online) 
protein-coupled receptor-54 (GPR54), have been known to play a key role in the activation of the gonadotropic axis at puberty. The aim of this review is to summarize a fundamental role of kisspeptin/GPR54 system in puberty onset.

\section{Discovery of kisspeptin/GPR54 system: from cancer biology to reproductive function}

Discovery of KISS1/GPR54 system took place in the field of cancer biology. In 1996, KISS1 mRNA was found to be overexpressed in melanoma cells with low metastatic activity; thus, KISS1 gene was originally regarded as a metastasissuppressor gene ${ }^{10)}$. In 2001, it was reported that the peptide products of the KISS1 gene conduct their biological activities through binding to a previously orphan, G protein-coupled receptor called GPR54 ${ }^{11-13)}$. This receptor was cloned in 1999. The KISS1 peptides were termed kisspeptins, as they derive from the differential proteolytic processing of a common precursor $^{11)}$. The major product of KISS1 appeared to be a 54-amino acid peptide called kisspeptin-54, which is mainly secreted by the placenta ${ }^{12)}$. In addition, other peptide fragments of KISS1 precursor, such as kisspeptin-14, kisspeptin-13, and kisspeptin-10, were also identified ${ }^{11)}$. All kisspeptins share the C-terminal region of kisspeptin-54 and all are equally potent in terms of activation of GPR54.

Even though kisspeptins and GPR54 originally attracted the attention of cancer biologists, initial expression and functional studies already suggested that this system may be provided with biological functions other than metastasis suppression. A striking finding in this sense was the widespread pattern of expression of GPR54 and, to a lesser extent, KISS1 genes in diverse normal human and rodent tissues. Thus, GPR54 gene expression appeared widely distributed, with maximal mRNA levels in placenta, pancreas, pituitary, spinal cord and different brain areas, including hypothalamus. In addition, prominent expression of the KISS1 gene was demonstrated in human placenta and, at lower levels, in the testis and small intestine. KISS1 mRNA was also detected in the human brain ${ }^{12,13}$. These findings strongly suggested the potential involvement of kisspeptine/GPR54 system in the physiological control of diverse biological systems, from placenta to several brain functions.

\section{Kisspeptins in reproduction: neuroendocrine control of reproduction}

The initial finding for the reproductive dimension of the kisspeptin/GPR54 system took place in late 2003. Investigators reported that loss-of-function mutations of the GPR54 gene are found in patients with idiopathic hypogonadotropic hypogonadism ${ }^{14,15)}$. It was also reported that mice genetically engineered to lack the GPR54 gene were found to be a complete phenocopy of affected humans ${ }^{15,16)}$. Hypothalamic GnRH synthesis and neuronal migration were conserved in these models, and pituitary responsiveness to GnRH preserved. It was suggested that the observed hypogonadotropism derives from a functional defect primarily located at the level of GnRH secretion, likely due to the lack of an essential upstream regulator of GnRH release $\mathrm{e}^{17)}$.

After unraveling of the reproductive dimension of kisspeptins, quite some effort was initially devoted to demonstrate whether kisspeptins were actually able to regulate gonadotropin secretion. Thus, a number of studies in laboratory animals and related species (rat, mouse, macaque and sheep) provided evidence that kisspeptin-54 and kisspeptin-10 are extraordinary potent elicitors of luteinizing hormone and follicle stimulating hormone (FSH) release, either after intracerebral or systemic (intravenous, intraperitoneal, and subcutaneous) administration of the peptides ${ }^{18-22)}$. These studies demonstrated that the responses to kisspeptin in terms of luteinizing hormone (LH) and FSH release were dose dependent. Altogether, these studies demonstrated that the sensitivity of the gonadotropic system to the stimulatory effect of kisspeptin is extraordinary high ${ }^{18,22)}$. Likewise, it has recently been reported that intravenous administration of doses as low as $0.1 \mu \mathrm{g}$ to adult rats, or $2 \mu \mathrm{g}$ to juvenile monkeys, are sufficient to elicit unambiguous LH secretory bursts $^{23,24)}$. Comparative analyses of the sensitivity and biopotency of kisspeptins and other well-known LH secretagogues indicate that kisspeptins are the most potent elicitors of the GnRH-gonadotropin axis. In agreement with data obtained in experimental animals, it was demonstrated that peripheral administration of kisspeptin-54 is able to stimulate LH secretion in humans ${ }^{25)}$.

Concerning the primary sites of action of kisspeptins on the reproductive axis, it is indicated that their gonadotropinreleasing effects come from the ability to activate $\mathrm{GnRH}$ release at the hypothalamus. More than $75 \%$ of GnRH neurons in the rat hypothalamus coexpress GPR54 mRNA ${ }^{26)}$, and central administration of kisspeptin induced c-fos expression (as early marker of activation) in more than $85 \%$ of $\mathrm{GnRH}$ neurons ${ }^{26)}$. Moreover, kisspeptin elicited GnRH secretion by rat hypothalamic explants ex vivo ${ }^{21,27)}$, and induced the release of GnRH in vivo in sheep ${ }^{17)}$. Taken together, these data it is strongly suggested that kisspeptins directly activate hypothalamic GnRH neurons, causing stimulation of GnRH secretion, which in turn elicits LH and FSH release from the pituitary.

Their ability to stimulate GnRH neurons is now indisputable, but the possibility of direct pituitary effects of kisspeptins in the control of gonadotropin secretion remains controversial. Of note, prominent expression of the GPR54 gene was initially reported in the human pituitary, but the functional role of KISS1 signaling at this site remains unclear. Functional studies reported to date, assessing direct stimulatory actions of kisspeptins on gonadotropin secretion at the pituitary, have demonstrated either no effects or moderate stimulatory actions of kisspeptins upon LH secretion in vitro ${ }^{19,21,22)}$. Nonetheless, whether GPR54 signaling at the pituitary may play a physiological role in the modulation of gonadotropin secretion, or in additional endocrine or nonendocrine functions, cannot be ruled out and 
requires further study.

\section{Kisspeptins and puberty onset}

As stated in previous sections, the indispensable role of the kisspeptin/GPR54 system in the control of puberty was disclosed by the initial findings of sexual immaturity in humans and mice carrying inactivating mutations of the GPR54 gene ${ }^{14-}$

16). Upon these seminal observations, analyses of KISS1 and GPR54 mRNA levels at the hypothalamus were conducted to ascertain potential developmental changes in the expression of those genes. In the rat, male and female animals showed a clearcut increase in KISS1 and GPR54 mRNA levels coinciding with the onset of puberty ${ }^{20)}$. This phenomenon was later confirmed in primates, in which KISS1 and GPR54 mRNA expression increased less than threefold at the hypothalamus during the transition from the juvenile to the midpubertal stage of the female. Similarly, hypothalamic KISS1 mRNA levels were raised in male monkeys during puberty ${ }^{28)}$. These initial studies suggested that there is an increase in kisspeptin signaling at the time of puberty (caused by enhanced expression of KISS1 and possibly GPR54), which could reasonably contribute to, or even drive, the activation of the gonadotropic axis that takes place during pubertal development.

This opinion was further supported by functional studies, conducted in animal, which confirmed the fundamental function of kisspeptins and GPR54 in the timing of puberty. Repeated administration of kisspeptin-10 to immature female rats was able to induce precocious vaginal opening and early activation of the gonadotropic axis ${ }^{29}$. Similarly, repetitive administration of kisspeptin-10 at the end of the juvenile phase of primate development elicited, in a precocious manner, a sustained train of $\mathrm{GnRH}$ discharges, similar to that found during puberty ${ }^{24)}$. In human studies, it was demonstrated that serum kisspeptin level was significantly higher in girls with central precocious puberty than in their age-matched prepubertal controls ${ }^{30,31)}$.

Altogether, these findings show that activation of GPR54 is sufficient to trigger the neuroendocrine events leading to puberty onset. However, the mechanisms by which hypothalamic kisspeptin plays as a switch for the onset of puberty seem to be multifaceted. By the use of electrophysiological studies and functional tests, Han el al. $^{32)}$ demonstrated that responsiveness of GnRH neurons to kisspeptin is enhanced along postnatal maturation. Thus, while only $27 \%$ of GnRH neurons were activated by kisspeptin in juvenile mice, more than $90 \%$ of GnRH neurons were depolarized by kisspeptin in adult animals. Moreover, the sensitivity of the GnRH system to kisspeptin was dramatically enhanced in adult versus juvenile mice ${ }^{32)}$. According to this work, activation of GnRH neurons at puberty may result from the combined increase in kisspeptin tone and enhancement of GPR54 signaling efficiency in GnRH neurons. This sophisticated mode of action illustrates the fundamental role of kisspeptins and GPR54 in normal pubertal development. It remains to be established, however, whether kisspeptin/GPR54 system is the trigger of mammalian puberty, or the ultimate effector of hierarchically higher regulatory factors.

\section{Kisspeptins and the regulation of puberty by energy status}

As indicated in previous sections, puberty onset is extremely sensitive to adequacy of nutrition and energy reserves of the organism. The neuroendocrine basis for such a phenomenon has begun to be unraveled recently, and is yet to be fully elucidated. While the roles of different peripheral hormones, such as leptin (adipose hormone signaling energy abundance) and ghrelin (gut-derived hormone signaling energy insufficiency) in the integrated control of energy balance and reproduction is now well established ${ }^{6,7)}$, the central circuits and signals relaying the state of energy stores onto the centers governing reproduction remain unclear. On the basis of their biological properties, kisspeptins were hypothesized as candidates for ultimately conveying metabolic cues (likely signaled via peripheral hormones) onto GnRH neurons at puberty.

To explore this hypothesis, studies on the expression and function of the kisspeptin/GPR54 system in conditions of energy insufficiency at puberty were conducted. These studies showed that short-term fasting induces a decrease in the expression of KISS1 mRNA and a concomitant increase in GPR54 mRNA at the hypothalamus of pubertal male and female rats. Moreover, LH responses to kisspeptin in vivo and $\mathrm{GnRH}$ responses in vitro were significantly augmented in fasting conditions. These findings suggest that a decrease in central KISS 1 tone occurs at conditions of negative energy balance, which may in turn lead to inhibition of the gonadotropic axis ${ }^{27)}$. More importantly, repeated administration of kisspeptin in a model of undernutrition of immature female rats, in which the decrease by $30 \%$ of daily food intake blunted normal pubertal development, was sufficient to restore vaginal opening (as external index of puberty) in a significant number of animals (60\%), and induced robust gonadotropin and estrogen responses in all rats treated with kisspeptin ${ }^{27)}$. Altogether, these findings demonstrate the close interaction between energy status and the hypothalamic KISS1 system, which may be a target for suppression of pubertal development and reproductive function in conditions of energy insufficiency.

Based on its prominent function in signaling the magnitude of fat reserves to reproductive centers, and its fundamental role in puberty onset, leptin was suspected to operate as a peripheral modulator of KISS1 neurons. Conclusive proofs for such a leptin-kisspeptin connection have just been reported, as more than $40 \%$ of KISS1 neurons have been demonstrated to express leptin receptors, leptin-deficient ob/ob mice were shown to have decreased KISS1 gene expression at the hypothalamus, and leptin treatment was able to partially rescue defective hypothalamic KISS1 mRNA levels in the ob/ob mouse ${ }^{33)}$. These 
findings support that the mechanism through which leptin modulates puberty onset includes the regulation of KISS1 expression at the hypothalamus.

\section{Conclusions}

Recently, the emergence of kisspeptins and GPR54 as fundamental regulators of reproduction has been observed. Characterization of the reproductive facet of kisspeptin/ GPR54 system has allowed the definition of its fundamental role in the regulation of gonadotropin secretion. Kisspeptins are likely the most powerful elicitors of the GnRH-LH axis. More importantly, the hypothalamic KISS1 system appears to be provided with essential physiologic functions, since it operates as a central conduit for key peripheral regulators of the gonadotropic axis, such as gonadal steroids, which regulate the hypothalamic expression of the KISS1 gene in a nucleus-specific manner, in accordance with their role in negative and positive feedback loops ${ }^{20,33)}$. This also seems to be the case for metabolic hormones, such as leptin, whose modulation of GnRH function is likely conveyed through intermediate KISS1 neurons ${ }^{34)}$. In the context of this review, the original contention that kisspeptins and GPR54 play an indispensable role in pubertal maturation ${ }^{15)}$ has now been fully confirmed by a combination of expression analyses and functional tests that have provided conclusive evidence for the enhancement of hypothalamic KISS1 expression and GPR54 signaling along puberty in rodent and primate species ${ }^{20,28,32)}$. Moreover, these studies have demonstrated the ability of kisspeptins to precociously activate the gonadotropic axis in immature rats and monkeys ${ }^{24,29)}$, and to rescue puberty onset in conditions of negative energy balance $^{27)}$. Nevertheless, although its role as activator of $\mathrm{GnRH}$ secretion at puberty is now clear, it remains to be established whether kisspeptin is the primary trigger for puberty onset, or if it operates (in conjunction with other signals) as an ultimate effector of upstream regulatory factors.

Despite the rapid progress in the knowledge of their reproductive functions, several aspects of this new dimension of the physiology of kisspeptins remain to be fully characterized. Further characterization of the fundamental role of kisspeptins and GPR54 as gatekeepers of puberty onset and reproductive function are needed.

\section{Conflict of interest}

No potential conflict of interest relevant to this article was reported.

\section{References}

1. Ojeda SR, Skinner MK. Puberty in the rat. In: Neill JD, editor. The physiology of reproduction. 3rd ed. San Diego: Academic Press/Elsevier, 2005:2061-26.

2. Tena-Sempere M, Huhtaniemi I. Gonadotropins and gonadotropin receptors. In: Fauser BC, editor. Reproductive medicine: molecular, celluar and genetic fundamentals. New York: Parthenon Publishing, 2003:225-44.

3. Parent AS, Teilmann G, Juul A, Skakkebaek NE, Toppari J, Bourguignon JP. The timing of normal puberty and the age limits of sexual precocity: variations around the world, secular trends, and changes after migration. Endocr Rev 2003;24:668-93.

4. Terasawa E, Fernandez DL. Neurobiological mechanisms of the onset of puberty in primates. Endocr Rev 2001;22:11151.

5. Ojeda SR, Lomniczi A, Mastronardi C, Heger S, Roth C, Parent AS, et al. Minireview: the neuroendocrine regulation of puberty: is the time ripe for a systems biology approach? Endocrinology 2006;147:1166-74.

6. Casanueva FF, Dieguez C. Neuroendocrine regulation and actions of leptin. Front Neuroendocrinol 1999;20:317-63.

7. Barreiro ML, Tena-Sempere M. Ghrelin and reproduction: a novel signal linking energy status and fertility? Mol Cell Endocrinol 2004;226:1-9.

8. Seeley RJ, York DA. Fuel sensing and the central nervous system (CNS): implications for the regulation of energy balance and the treatment for obesity. Obes Rev 2005;6:259-65.

9. Cunningham MJ, Clifton DK, Steiner RA. Leptin's actions on the reproductive axis: perspectives and mechanisms. Biol Reprod 1999;60:216-22.

10. Lee JH, Miele ME, Hicks DJ, Phillips KK, Trent JM, Weissman BE, et al. KiSS-1, a novel human malignant melanoma metastasis-suppressor gene. J Natl Cancer Inst 1996;88:1731-7.

11. Kotani M, Detheux M, Vandenbogaerde A, Communi D, Vanderwinden JM, Le Poul E, et al. The metastasis suppressor gene KiSS-1 encodes kisspeptins, the natural ligands of the orphan G protein-coupled receptor GPR54. J Biol Chem 2001;276:34631-6.

12. Ohtaki T, Shintani Y, Honda S, Matsumoto H, Hori A, Kanehashi K, et al. Metastasis suppressor gene KiSS-1 encodes peptide ligand of a G-protein-coupled receptor. Nature 2001;411:613-7.

13. Muir AI, Chamberlain L, Elshourbagy NA, Michalovich D, Moore DJ, Calamari A, et al. AXOR12, a novel human G protein-coupled receptor, activated by the peptide KiSS-1. J Biol Chem 2001;276:28969-75.

14. de Roux N, Genin E, Carel JC, Matsuda F, Chaussain JL, Milgrom E. Hypogonadotropic hypogonadism due to loss of function of the KiSS1-derived peptide receptor GPR54. Proc Natl Acad Sci U S A 2003;100:10972-6.

15. Seminara SB, Messager S, Chatzidaki EE, Thresher RR, Acierno JS Jr, Shagoury JK, et al. The GPR54 gene as a regulator of puberty. N Engl J Med 2003;349:1614-27.

16. Funes S, Hedrick JA, Vassileva G, Markowitz L, Abbondanzo S, Golovko A, et al. The KiSS-1 receptor GPR54 is essential for the development of the murine reproductive system. Biochem Biophys Res Commun 2003;312:1357-63. 
17. Messager S. Kisspeptin and its receptor: new gatekeepers of puberty. J Neuroendocrinol 2005;17:687-8.

18. Gottsch ML, Cunningham MJ, Smith JT, Popa SM, Acohido BV, Crowley WF, et al. A role for kisspeptins in the regulation of gonadotropin secretion in the mouse. Endocrinology 2004; 145:4073-7.

19. Matsui H, Takatsu Y, Kumano S, Matsumoto H, Ohtaki T. Peripheral administration of metastin induces marked gonadotropin release and ovulation in the rat. Biochem Biophys Res Commun 2004;320:383-8.

20. Navarro VM, Castellano JM, Fernandez-Fernandez R, Barreiro ML, Roa J, Sanchez-Criado JE, et al. Developmental and hormonally regulated messenger ribonucleic acid expression of KiSS- 1 and its putative receptor, GPR54, in rat hypothalamus and potent luteinizing hormone-releasing activity of KiSS-1 peptide. Endocrinology 2004;145:456574.

21. Thompson EL, Patterson M, Murphy KG, Smith KL, Dhillo WS, Todd JF, et al. Central and peripheral administration of kisspeptin-10 stimulates the hypothalamic-pituitarygonadal axis. J Neuroendocrinol 2004;16:850-8.

22. Navarro VM, Castellano JM, Fernandez-Fernandez R, Tovar S, Roa J, Mayen A, et al. Characterization of the potent luteinizing hormone-releasing activity of KiSS-1 peptide, the natural ligand of GPR54. Endocrinology 2005;146:15663.

23. Tovar S, Vazquez MJ, Navarro VM, Fernandez-Fernandez $\mathrm{R}$, Castellano JM, Vigo E, et al. Effects of single or repeated intravenous administration of kisspeptin upon dynamic LH secretion in conscious male rats. Endocrinology 2006;147:2696-704.

24. Plant TM, Ramaswamy S, Dipietro MJ. Repetitive activation of hypothalamic G protein-coupled receptor 54 with intravenous pulses of kisspeptin in the juvenile monkey (Macaca mulatta) elicits a sustained train of gonadotropinreleasing hormone discharges. Endocrinology 2006;147:1007-13.

25. Dhillo WS, Chaudhri OB, Patterson M, Thompson EL, Murphy KG, Badman MK, et al. Kisspeptin-54 stimulates the hypothalamic-pituitary gonadal axis in human males. J Clin Endocrinol Metab 2005;90:6609-15.

26. Irwig MS, Fraley GS, Smith JT, Acohido BV, Popa SM, Cunningham MJ, et al. Kisspeptin activation of gonadotropin releasing hormone neurons and regulation of KiSS-1 mRNA in the male rat. Neuroendocrinology 2004;80:264-72.

27. Castellano JM, Navarro VM, Fernandez-Fernandez R, Nogueiras R, Tovar S, Roa J, et al. Changes in hypothalamic KiSS-1 system and restoration of pubertal activation of the reproductive axis by kisspeptin in undernutrition. Endocrinology 2005; 146:3917-25.

28. Shahab M, Mastronardi C, Seminara SB, Crowley WF, Ojeda SR, Plant TM. Increased hypothalamic GPR54 signaling: a potential mechanism for initiation of puberty in primates. Proc Natl Acad Sci U S A 2005;102:2129-34.

29. Navarro VM, Fernandez-Fernandez R, Castellano JM, Roa J, Mayen A, Barreiro ML, et al. Advanced vaginal opening and precocious activation of the reproductive axis by KiSS1 peptide, the endogenous ligand of GPR54. J Physiol 2004;561(Pt 2):379-86

30. Rhie YJ, Lee KH, Eun SH, Choi BM, Chae HW, Kwon AR, et al. Serum kisspeptin levels in Korean girls with central precocious puberty. J Korean Med Sci 2011;26:927-31.

31. de Vries L, Shtaif B, Phillip M, Gat-Yablonski G. Kisspeptin serum levels in girls with central precocious puberty. Clin Endocrinol (Oxf) 2009;71:524-8.

32. Han SK, Gottsch ML, Lee KJ, Popa SM, Smith JT, Jakawich SK, et al. Activation of gonadotropin-releasing hormone neurons by kisspeptin as a neuroendocrine switch for the onset of puberty. J Neurosci 2005;25:11349-56.

33. Smith JT, Dungan HM, Stoll EA, Gottsch ML, Braun RE, Eacker SM, et al. Differential regulation of KiSS-1 mRNA expression by sex steroids in the brain of the male mouse. Endocrinology 2005;146:2976-84.

34. Smith JT, Acohido BV, Clifton DK, Steiner RA. KiSS-1 neurones are direct targets for leptin in the ob/ob mouse. J Neuroendocrinol 2006;18:298-303. 